\title{
CARBONO, NITROGÊ NIO E ENXOFRE EM FRAÇÕES GRANULOMÉTRICAS DE DOIS LATOSSOLOS SUBMETIDOS À CALAGEM E ADUBAÇÃO FOSFATADA ${ }^{(\mathbf{1})}$
}

\author{
C. A. SILVA ${ }^{(2)}$, S. J . ANDERSON ${ }^{(3)} \&$ F. R. VALE ${ }^{(4)}$
}

\begin{abstract}
RESUMO
Os teores e a distribuição de carbono, nitrogênio e enxofre em frações granulométricas do solo foram anali sados em dois L atossolos Vermel ho-E scuros, um derivado de floresta (LE 1) e outro de cerrado (LE 2). O LE 1, de Cordeirópolis, SP, corresponde a um solo cultivado com laranja desde 1982, sem e com calagem. O cultivo do LE 2 (Planaltina, DF) foi iniciado em 1976, com o plantio de trigo, soja, arroz e sorgo, sendo esse solo cultivado nos últimos 14 anos com pastagem (Andropogon gayanus L.), sem e com uma única aplicação de $1.660 \mathrm{~kg} \mathrm{ha}^{-1}$ de $\mathrm{P}_{2} \mathrm{O}_{5}$, na forma de superfosfato triplo. Para fins de referência, foram coletadas amostras adicionais do LE 1 e LE 2 em áreas sob vegetação natural. Foram determinados os teores de car bono, nitrogênio e enxofre em solo não fracionado e em suas frações granulométricas. A drástica redução nos teores de carbono, nitrogênio e enxofre do LE 1 com o cultivo resultou em diminuição da CTC na área sob calagem e na testemunha, indicando a importância do manejo e conservação da matéria orgânica nesse solo. No LE 2, a redução nos teores de carbono e nitrogênio com o cultivo foi menos intensa e associou-se à decomposi ção de compostos or gâni cos ligados à fração intermediária (2-53 mm). A calagem resultou em maior preservação de matéria orgânica no LE 1; não houve, porém, efeito do fósforo sobre os teores de C e N das áreas cultivadas do LE2. A fração fina $(<2 \mu \mathrm{m})$ exerceu papel crucial na estabilização da matéria orgânica nos solos estudados, já que os maiores reservatórios de carbono, nitrogênio e enxofre nas áreas cultivadas e sob vegetação natural encontravam-se associados a essa unidade granulométrica. Os principais efeitos do cultivo sobre os reservatórios de carbono, nitrogênio e enxofre do LE 1 estiveram associados ao enriquecimento relativo desses elementos na fração fina, às custas da decomposição de material orgânico associado às frações fina: $(<2 \mu \mathrm{m})$, intermediária (2-53 $\mu \mathrm{m})$ e grossa (53-2.000 $\mu \mathrm{m})$.
\end{abstract}

Termos de indexação: matéria orgânica, calagem, fósforo, dispersão física de solo.

\footnotetext{
(1) Parte da Tese de Doutorado do primeiro autor, apresentada à Universidade F ederal de Lavras - UFLA. Recebido para publicação em agosto de 1998 e aprovado em abril de 1999.

(2) Pesquisador da E mbrapa Solos. Rua J ardim Botânico, 1024, CEP 22460-000 Rio deJ aneiro (RJ ). E-mail: csilva@cnps.embrapa.br.

(3) Professora da California State Universisty at Monterey. Seaside, CA (USA) 93955.

(4) Professor do Departamento de Ciência do Solo, UFLA. Caixa Postal 37, CEP 37200-000 Lavras (MG).
} 


\title{
SUMMARY: CARBON, NITROGEN AND SULFUR IN PARTICLE SIZE FRACTIONS OF TWO OXISOLS SUBMITTED TO THE ADDITION OF LIMING AND PHOSPHORUS
}

\begin{abstract}
Theamount and distribution of carbon, nitrogen, and sulfur in whol esoil and in particle sizefractions wereanalyzed in two clayey Dark Red Latosols (LE 1 and LE2). LE 1 (forest as natural vegetation), from Corder rópolis, SãoPaulo, cultivated with citrus since 1982 receiving two limetreatments, control and 18 t ha-1 applied twicein 1983 and 1994. Since 1976, LE2 (cerrado as natural vegetation) from Planaltina, Federal District (cerrado region), was cultivated with different crops (wheat, soybean, rice and sorghum) sown for 14 years with pasture grass (Andropogon gayanus L.), with and without the addition of $1.660 \mathrm{~kg} \mathrm{ha}^{-1}$ of $\mathrm{P}_{2} \mathrm{O}_{5}$ as triple superphosphate $\mathrm{F}$ or reference purposes, additional samples were collected from uncropped soi Is in both LE 1 and LE 2 sites. Carbon, nitrogen and sul fur contents were determined in wholesoils and in their particlesizefractions. Thedrastic reduction of carbon, nitrogen and sulfur contents in the cultivated areas of LE 1 was followed by an intensive depletion in CEC at limed and control plots, stressing the importance of management and conservation of organic matter in this soil. In the LE 2 soil, the reduction of $\mathrm{C}, \mathrm{N}$ and $\mathrm{S}$ contents with cultivation was less intense and associated with a higher decomposition of organic compounds linked to the intermediate fraction. Liming resulted in a higher preservation of soil organic matter, although phosphorus addition did not affect carbon and nitrogen contents in the LE2 cultivated areas. Fine fraction plays a crucial role in the stabi lization of soil organic matter, sincethelargest reservoirs of carbon, nitrogen and sul fur wereassociated to this particlesize. Thedistribution of carbon, nitrogen and sulfur between particlesize fractions is characterized by a depletion of organic materials associated to coarse intermediateand finefractions and a shift towards finefraction associated materials.
\end{abstract}

Index terms: Organic matter, liming, phosphorus, soil physical dispersion.

\section{NTRODUÇÃO}

A matéria orgânica do solo (MOS) engloba não só resíduos de plantas, animais e microrganismos em diver sos estádios de decomposição, mas também um vasto número de frações orgânicas em íntima associação com a fase mineral dos sol os (Christensen, 1992). Entender melhor essas associações organo minerais, em ambientes naturais e agrícolas, constitui etapa indispensável à mel hor compreensão das inter-relações existentes entre a matéria orgânica e os processos de erosão de solo, ciclagem de nutrientes, despoluição de solo e de emissão de $\mathrm{CO}_{2}$ e outros gases para a atmosfera (Guggenberger et al., 1994).

No Brasil, esses estudos são ainda mais importantes, visto que proedominam, no País, solos ácidos al tamenteintemperizados, com baixa reserva de nutrientes e com presença de argilas, quartzo, óxidos e sesquióxidos de Fe e Al de baixa atividade. Nessas condições, a matéria orgânica (MO) desempenha papel de extrema importância na determinação do nível de fertilidade do solo e produtividade das culturas, pois énessa matriz que seencontra o mai or reservatóri o de cargas nos sol os brasileiros.
A dinâmica da matéria orgânica é governada pelo clima, tipo de sol o e práticas de manejo (Amelung et al., 1998). Para um mesmo tipo de solo, é o sistema de manejo que regula a qualidade e quantidade de matéria orgânica e, por conseqüência, a composição eatividade de organismos decompositores eas taxas de perda de carbono por mineralização, lixiviação e erosão (Feller \& Beare, 1997).

O estoque de matéria orgânica no sol o relacionase diretamente com a intensidade dos processos de adição de resíduos vegetais e de decomposição de frações orgânicas. Em solos sob vegetação natural, a preservação de matéria orgânica tende a ser máxima, pois orevolvimento do soloémínimo, sendo o aporte de carbono nas florestas mais elevado do que em áreas cultivadas (Lathwell \& Bouldin, 1981; Nobre \& Gash, 1997). Em áreas cultivadas, os teores de matéria orgânica, via de regra, diminuem, já que as frações orgânicas são mais expostas ao ataque de microrganismos, dependendo do mai or revolvimento e desestruturação do solo (Resck et al., 1991). A correção da aci dez do sol o e a adição de fertilizantes estimulam a atividade microbiana e, por conseqüência, podem resultar em maior taxa de mineralização da matéria orgânica, com perda de carbono do solo, via $\mathrm{CO}_{2}$ (Marschner \& Wilczynski, 
1991). Por outrolado, a aplicação de cal cário em sol os brasileiros resulta em incremento na produtividade da maioria das culturas e no aporte de carbono ao solo, principalmente se permanecem resíduos vegetais nas áreas de plantio, sendo, desse modo, difícil prever o efeito dessa prática sobre os estoques de matéria orgânica no solo.

$\mathrm{Na}$ maioria dos solos, as frações orgânicas encontram-se mais associadas à argila e ao silte, de forma que as quantidades de carbono e nitrogênio associadas à areia não perfazem mais do que $10 \%$ (Rosell et al., 1996). Apesar de contribuir somente com pequena parte da matéria orgânica presente nos solos, é à areia que se associam as frações orgânicas de maior biodisponibilidade, em relação àquelas ligadas a argila e silte (Christensen, 1996). Tal fato se deve ao processo de separação da areia das demais partículas texturais, na medida em que, durante a dispersão dos sol os, mais especificamente na etapa de peneiramento, agrega-se à areia material orgânico particulado, com grau de decomposição mais próximo ao de resíduos vegetais recentemente adicionados aos solos. À argila e, com menor intensidade, ao silte, ligam-se compostos de relação $\mathrm{C}: \mathrm{N}$ baixa, normalmente resultantes do metabolismo de microrganismos (Christensen, 1996).

Em áreas onde predominam a remoção intensiva de resíduos vegetais da área de plantio e o preparo excessivo do solo, as perdas de carbono e nitrogênio do sistema solo-planta são acentuadas, dependendo do aumento na taxa de mineralização das frações menos decompostas associadas à argila e, principalmente, à areia (Guggenberger et al., 1994, Feller \& Beare, 1997). Tais práticas de manejo acarretam intensa diminuição nos níveis de matéria orgânica do solo como um todo (Silva et al., 1994) e enriquecimento relativo de compostos com el evado grau de decomposi ção na argila (Tiessen \& Stewart, 1983).

Diante detais considerações, torna-se necessário lançar mão de técnicas que monitorem essas mudanças indesejáveis, com vistas em identificar práticas de manejo mais conservacionistas, que resultem em maior preservação e armazenamento de carbono, nitrogênio e enxofre nos solos. Quando associada às análises químicas, biológicas e físicas, a técnica de dispersão física do sol o se presta bem a esse objetivo, na medida em que permite identificar a distribuição, a composição química e o grau de decomposição de frações orgânicas expostas a diferentes sistemas de manejo (Christensen, 1992).

O presente estudo baseou-se na técnica de dispersão física de solo com ultra-som a fim de avaliar os efeitos da calagem e da adição de fósforo sobre os teores e distribuição de carbono, nitrogênio e enxofre em frações granulométricas de dois Latossol os cultivados e sob vegetação natural.

\section{MATERIAL E MÉTODOS}

\section{Solos}

Dois solos com a mineralogia da fração argila dominada por caulinita e gibbsita foram coletados no mês de novembro de 1995. I nicial mente, col etouse no campo experimental decitricultura do I AC em Cordeirópolis, SP, a unidade Latossolo Vermel hoEscuro (LE 1) textura muitoargil osa, sob floresta (FI, cerca de $1.500 \mathrm{~m}$ distante da área experimental) e sob cultivo nos últimos 13 anos com laranja, em área ondea calagem foi praticada (Calc) e na testemunha (Test, cultivo sem correção da acidez do solo).

Os materiais de solo do LE 1 foram col etados na profundidade de 0-10 cm, em três repetições, por meio da amostragem, em cada parcela, de quatro pontos sob as copas das laranjeiras, sendo esses materiais de solo misturados, para obter a amostra composta utilizada nas análises. A correção da acidez do sol o se deu pela aplicação a lanço de 18 t ha-1 de calcário (9t de calcário calcítico + 9 t de calcário dol omítico), noano de 1983, por ocasião da instalação do experimento e plantio das Iaranjeiras e, em 1994, aplicando-senovamente 18 t ha-1 decal cário, visando à restituição dos níveis de $\mathrm{pH}$ e bases trocáveis de 1983. N essa etapa, o calcário foi aplicado a lanço e incorporado com grade leve. $\mathrm{Na}$ área experimental com Iaranja, o controle das ervas daninhas, predominantemente gramíneas, foi efetuado, usando-se roçadeira nas entrelinhas e capina sob a copa das Iaranjeiras. Numa fase anterior ao estabel ecimento do experimento com as Iaranjei ras, a área amostrada foi utilizada por cerca de vinte anos com pastagens.

A segunda unidade de solo foi coletada em Latossolo Vermelho-Escuro (LE 2), no campo experimental da Embrapa Cerrados. A caracterização química e a textura dos solos LE 1 e LE2 são apresentadas no quadro 1. A pós a derrubada do cerrado e antes do primeiro plantio, a área experimental amostrada do LE 2 recebeu 2,2 t ha- 1 de calcário dolomítico e adubação corretiva de potásssio (150 kg ha-1 de $_{2} \mathrm{O}$, na forma de $\mathrm{KCl}$ ) e de micronutrientes (40 kg ha-1 de FTE BR-10). Em janeiro de 1976, foi semeado o trigo; em novembro de 1976 e 1977, a soja e, em novembro de 1978, o arroz. No ano de 1979, efetuou-se o plantio de sorgo, que foi cultivado até 1980. Nas culturas de trigo e arroz, foram aplicados $30 \mathrm{~kg}$ ha-1 de N, em cobertura. O plantio do capim andropogon (Andropogon gayanus L.) se deu no ano agrícola de 1980/81, sendo esta gramínea cultivada até 1995, ano de encerramento do experimento. O manejo do capim andropogon até 1987 consistiu de dois cortes/ano dessa gramínea. A partir daí, os tratos culturais na área experimental restringiram-sea uma passagem de roçadeira nas parcelas com capim andropogon, com permanência dos restos culturais na área de plantio. Nos últimos quatroanos de cultivo, o capim 
Quadro 1. Características químicas e textura do Latossolo Vermelho-E scuro derivado de floresta (LE 1), e de cerrado (LE 2)

\begin{tabular}{|c|c|c|c|c|c|c|c|c|c|}
\hline Solo/tratamento ${ }^{(1)}$ & $\mathbf{p H} \mathbf{H}_{2} \mathbf{O}$ & $\mathbf{P}$ & CTC $^{(2)}$ & $\mathrm{Ca}$ & $\mathbf{m}^{(3)}$ & $\mathbf{V}^{(4)}$ & Argila & Silte & Areia \\
\hline & & $\mathrm{mg} \mathrm{kg}^{-1}$ & $-\mathrm{cmol}$ & $n^{-3}-$ & 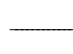 & - & 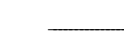 & $-\mathrm{g} \mathrm{kg}^{-1}$ & - \\
\hline \multicolumn{10}{|l|}{ LE 1} \\
\hline $\begin{array}{l}\text { Floresta } \\
\text { Com calagem } \\
\text { Sem calagem }\end{array}$ & $\begin{array}{l}3,9 \\
6,6 \\
4,2\end{array}$ & $\begin{array}{r}2 \\
43 \\
21\end{array}$ & $\begin{array}{l}17,1 \mathrm{a} \\
10,3 \mathrm{c} \\
11,4 \mathrm{~b}\end{array}$ & $\begin{array}{l}0,8 \\
5,9 \\
0,8\end{array}$ & $\begin{array}{r}71 \\
1 \\
60\end{array}$ & $\begin{array}{r}7 \\
80 \\
12\end{array}$ & $\begin{array}{l}680 \\
680 \\
690\end{array}$ & $\begin{array}{l}140 \\
120 \\
110\end{array}$ & $\begin{array}{l}180 \\
200 \\
200\end{array}$ \\
\hline \multicolumn{10}{|l|}{ LE 2} \\
\hline $\begin{array}{l}\text { Cerrado } \\
+P \\
-P\end{array}$ & $\begin{array}{l}4,3 \\
4,7 \\
4,4\end{array}$ & $\begin{array}{l}1 \\
5 \\
1\end{array}$ & $\begin{array}{l}9,4 \mathrm{a} \\
7,3 \mathrm{c} \\
8,7 \mathrm{~b}\end{array}$ & $\begin{array}{l}0,4 \\
0,7 \\
0,5\end{array}$ & $\begin{array}{l}64 \\
45 \\
58\end{array}$ & $\begin{array}{r}6 \\
13 \\
9\end{array}$ & $\begin{array}{l}520 \\
510 \\
500\end{array}$ & $\begin{array}{l}160 \\
160 \\
140\end{array}$ & $\begin{array}{l}320 \\
330 \\
360\end{array}$ \\
\hline
\end{tabular}

(1) +P =área com fósforo; -P = área sem fósforo. ${ }^{(2)}$ As médias seguidas de letras distintas, na linha, diferem entre si pelo teste de Tukey a 5\%. ${ }^{(3)} \mathrm{m}=$ Percentagem de saturação por alumínio. ${ }^{(4)} \mathrm{V}=$ Percentagem de saturação por bases.

andropogon recebeu adubação, por meio da aplicação anual de $160 \mathrm{~kg} \mathrm{ha}^{-1}$ de $\mathrm{N}$ mais $160 \mathrm{~kg} \mathrm{ha}^{-1}$ de $\mathrm{K}_{2} \mathrm{O}$.

$\mathrm{Na}$ área experimental, cujo histórico foi descrito, foram amostradas duas parcelas: uma com a adição de fósforo (+P), na qual, noano de 1976, tinham sido adicionados $1.660 \mathrm{~kg} \mathrm{ha}-1$ de $\mathrm{P}_{2} \mathrm{O}_{5}$, na forma de superfosfato triplo, aplicado a lanço e incorporado por enxada rotativa, e uma segunda área cultivada sem a aplicação de fósforo (-P). Para fins de comparação, coletou-se também uma terceira área sob vegetação de cerrado (Cerr), a 200 m da área experimental.

A análise granulométrica foi efetuada pelo método da pipeta (Gee \& Bauder, 1986). Basicamente, adicionaram-se $200 \mathrm{~mL}$ de $\mathrm{NaOH}$ 0,1 M a $50 \mathrm{~g}$ desolo, agitando-sea sol ução por $30 \mathrm{~min}$ em agitador do tipo 'milk-shaker', sendo a areia separada do silte e argila por meio de tamisamento (53 $\mu \mathrm{m})$. A separação da argila do silte baseou-se no princípio de sedimentação diferenciada dessas duas frações em soluções aquosas.

A análisequímica dos solos foi real izada de acordo com os métodos da EMBRAPA (1979), sendo determinados o $\mathrm{pH}$ em água, os teores de $\mathrm{Al} 3+, \mathrm{Ca}^{2+}$, $\mathrm{Mg}^{2+}, \mathrm{K}+\mathrm{e}$ o teor de fósforo disponível (Mehlich-1). A acidez potencial $\left(\mathrm{H}++\mathrm{Al}^{3+}\right)$ foi avaliada indir etamente, via medição do pH do extrato de solo em solução-tampão de Shoemaker, M cL ean e Pratt (SMP). A seguir, por meio dos parâmetros anteriormente descritos, calculou-se a saturação por bases e por al umínio dos solos. A capacidade detroca catiônica (CTC) em pH 7,0 foi estimada mediante a expressão: $\mathrm{CTC}=\left(\mathrm{H}^{+}+\mathrm{Al}^{3+}\right)+\mathrm{Ca}^{2}++\mathrm{Mg}^{2+}+\mathrm{K}+$, em $\mathrm{cmol}_{\mathrm{C}} \mathrm{kg}^{-1}$. As determi nações dos teores totais de carbono e nitrogênio nos sol os LE 1 e LE 2 e em suas frações granulométricas foram realizadas em anal isador automático de C/N/S Carlo E rba, modelo NA 1500, por meio da combustão das amostras em temperatura el evada $\left(900^{\circ} \mathrm{C}\right)$. O enxofre foi determinado por meio da combustão seca de uma mistura de 2,5 g de solo, ou fração textural, e $1,0 \mathrm{~g}$ de $\mathrm{NaHCO}_{3}$ a $500^{\circ} \mathrm{C}$, conforme Bardsl ey \& Lancaster (1960). O S-SO ${ }_{4}^{2-}$ oriundo dessa combustão foi extraído com solução de $\mathrm{Na}\left(\mathrm{H}_{2} \mathrm{PO}_{4}\right)_{2} \cdot \mathrm{H}_{2} \mathrm{O}$ em ácido acético $2 \mathrm{~N}$ e determinado por turbidimetria. Os resultados obtidos, aotérmi no dessas anál ises, foram expressos com base no teor de água presente nas amostras após secagem a $104^{\circ} \mathrm{C}$.

\section{Fracionamento físico dos solos}

Na dispersão física dos materiais de solo, seguiuse o método proposto por Christensen (1992), por meio do uso de ondas de ultra-som. Basicamente, $30 \mathrm{~g}$ de solo foram adicionados a $250 \mathrm{~mL}$ de água destilada, sendo essa suspensão sonificada durante 15 min (três intervalos de $5 \mathrm{~min}$ ), em sonificador Misonix, modelo W385. Para evitar o superaquecimento das amostras sonificadas, o béquer com a suspensão de solo era envolto em gelo. Ao término da etapa de sonificação, procedeu-se à separação de três frações granulométricas, com os seguintes diâmetros: 53-2.000 $\mu \mathrm{m}, 2-53 \mu \mathrm{m}$ e $<2 \mu \mathrm{m}$, respectivamente, denominadas fração grossa ( $\mathrm{Fr}$. grossa), fração intermediária (Fr. interm.) e fração fina ( $F r$. fina). A escol ha dessa nomenclatura baseouse no fato de que a recuperação dessas frações (grossa, intermediária e fina) pelo método de dispersão via sonificação representou de 92 a 98\% dos teores de argila, silte e areia determinados pelo método da pipeta. A separação da fração de 53$2.000 \mu \mathrm{m}$ das demais foi efetuada via tamisamento, enquanto a fração fina foi separada da intermediária por repetidas etapas de sedimentação, centrifugação (9.000 rpm, durante 10 min) e sonificação.

Os tratamentos dos dois experimentos analisados foram dispostos no campo em delineamento em 
blocos casual izados, sendo amostrados os três blocos de cada tratamento escol hido. Quando os fatores analisados foram significativos no teste de $\mathrm{F}$, a comparação das médias foi feita pel oteste de Tukey a 5\%, para cada caso, usando-se o "software" Sanest (Zonta \& Machado, 1980).

\section{RESULTADOS E DISCUSSÃO}

\section{Teores totais de carbono, nitrogênio e enxofre}

O cultivo do Latossolo Vermelho-Escuro sob floresta (LE 1) por mais de 33 anos resultou em drásticas perdas de matéria orgânica, apresentando a área sob floresta teores de carbono e nitrogênio quase duas vezes superiores aos da área com calagem (Calc) eaos da testemunha (Test, cultivada sem correção da acidez) (Figura 1). O cultivo das parcelas Calc e Test resultou numa diminuição de 42 e $48 \%$ do teor de $C$ do solo, respectivamente, em relação ao da área sob floresta do LE 1 . Os teores de nitrogênio foram reduzidos em 35\% na área com calagem e em $44 \%$ na testemunha. Os resultados obtidos estão de acordo com aqueles apresentados por Tiessen \& Stewart (1983); Vitorello et al. (1989); Resck et al. (1991); Bonde et al. (1992); Silva et al. (1994), os quais observaram redução drástica no conteúdo de matéria orgânica em sol os sob cultivo.

Demodo geral, a decomposiçãoda matéria orgânica em sol os tropicais sob cultivo é mais acelerada do que em solos sob florestas, havendo situações em que os estoques de carbono são reduzidos em mais de $50 \%$, em menos de 10 anos de cultivo (Shang \& Tiessen, 1997). Por exemplo, perdas sistemáticas de matéria orgânica, em cinco anos de plantio de soja em solos de cerrado do Oeste baiano, foram observadas por Silva et al. (1994), tendo-se constatado decréscimos de 80,76 e $41 \%$ do estoque inicial de matéria orgânica em Areia Quartzosa, Latossolo Vermelho-Amarelo textura média eL atossoloVermel ho-Amarelo argiloso, respectivamente.

Os estoques de matéria orgânica nos solos representam o balanço entre as práticas de manejo voltadas à incorporação de resíduos vegetais nas áreas de plantio e aquelas que resultam numa decomposição mais acelerada da matéria orgânica (Christensen, 1996). Nesse sentido, a floresta, dentre as três áreas estudadas do LE 1, é o local de menor perturbação de solo e, pela exuberância da vegetação, de maior aporte de matéria orgânica ao solo. Desse modo, as adições el evadas de resíduos vegetais, aliadas à maior proteção e a uma baixa taxa de decomposição da matéria orgânica do solo em área sob floresta (Shang \& Tiessen, 1997), contribuem sobremaneira para os teores el evados de carbono, nitrogênio e enxofre observados nesse ecossistema.

Por outro lado, é provável que as etapas de estabelecimento e renovação das pastagens e o plantio de Iaranja tenham contribuído para a redução acelerada nos teores de matéria orgânica, em virtude não só da maior exposição das frações orgânicas aos microrganismos decompositores, mas também da maior quebra de macroagregados pelo revol vimento do solo. Contudo, acredita-se que o fator que mais tenha contribuído para a decomposi ção da matéria orgânica seja o menor aporte de carbono e nitrogênio nas áreas cultivadas, em relação à floresta. Tal suposição justifica-se pelo fato de o manejo implementado nos últimos 13 anos decultivo de laranja ter sido bastante conservacionista, caracterizando-se pelo baixo revolvimento do solo e pela permanência dos restos de ervas daninhas nas áreas sob cultivo.

No Latossolo Vermel ho-E scuro, na área onde foi feita a cal agem, os teores de carbono e nitrogênio no solo foram mais altos, em relação à área cultivada sem correção da acidez (Figura 1). De modo geral, com a correção da acidez do solo, tem-se verificado
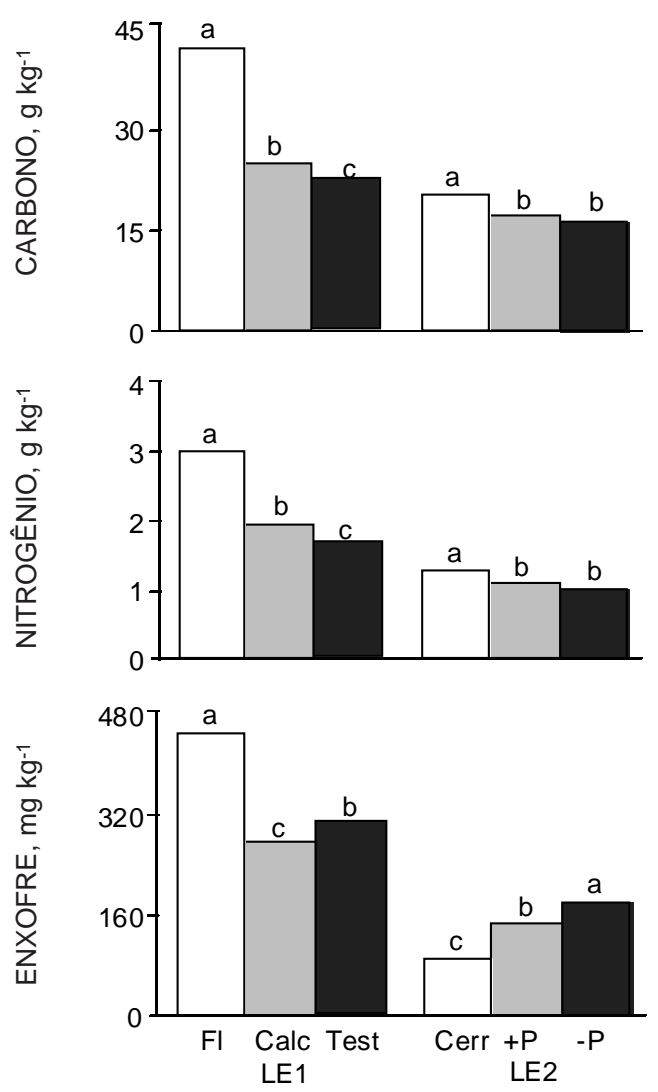

Figura 1. Concentrações de carbono, nitrogênio e enxofre no solo não fracionado de Latossolo Vermelho-E scuro derivado de floresta (LE 1) e de cerrado (LE2). Médias seguidas por letras diferentes, nas colunas, para cada solo, diferem entre si pelo teste de Tukey a $5 \%$. FI = floresta; Calc = área com calagem; Test = área sem calagem; Cerr =cerrado; $+\mathbf{P}$ =área com fósforo; -P = área sem fósforo. 
aumento nas taxas de mineralização da matéria orgânica (Roth et al., 1992; Kreutzer, 1995), muito embora, em algumas áreas, as quantidades de carbono perdidas via $\mathrm{CO}_{2}$ sejam menores nas áreas com calagem (Borken \& Brumme, 1997).

O desmatamento e o cultivo do Latossolo Vermel ho-E scuro sob cerrado (LE 2), tanto adubado como não adubado com fósforo, resultou em reduções nos teores de carbono e nitrogênio (Figura 1): os teores de C e N nas áreas cultivadas do LE 2 foram, em média, 20\% inferiores aos da área-controle de cerrado. Analisando os teores de matéria orgânica nas áreas cultivadas, é bastante provável que o plantio de culturas anuais na fase inicial de exploração da área desmatada do LE2, o maior revolvimento do sol o ea retirada de restos culturais das áreas sob cultivo tenham contribuído para uma decomposição mais acelerada da matéria orgânica.

Por outrolado, resíduos vegetais provenientes do cultivo de uma gramínea de relação C:N mais larga (capim andropogon), durante os últimos 15 anos de expl oração das parcelas adubada (+P) enão adubada (-P) com fósforo, bem como as práticas de menor revolvimento do solo e maior preservação de macroagregados nas áreas com capim, foram, provavelmente, os fatores que mais contribuíram para que as perdas de matéria orgânica não fossem tão drásticas nas áreas de sol o de cerrado sob cultivo. Os teores de carbono e nitrogênio nas áreas sob cultivo do LE2 não foram influenciados pela aplicação de fósforo (F igura 1), concordando com os resultados obtidos por Murata et al. (1995), quenão observaram alterações nos estoques de matéria orgânica em áreas de pastagens com a aplicação de até $388 \mathrm{~kg} \mathrm{ha}^{-1}$ ano-1 de superfosfato simples, embora, no presente estudo, a quantidade defósforo aplicada tenha sido bastante superior a esse valor.

Os teores deenxofre nas áreas Calce Test do LE 1 (originalmente solo de floresta) também sofreram reduções drásticas com o cultivo, sendo esse efeito mais acentuado na área com calagem (Figura 1). É provável que a correção da acidez do solo tenha estimulado o processo de mineralização de enxofre nesta área e, por conseguinte, ocasi onado mai or fluxo de sulfato para as camadas mais profundas do solo. Ao contrário, o cultivo do LE2 (originalmente sob cerrado) resultou em maior presença de enxofre no solo, visto que os teores de S no solo, nas parcelas IP e-P, foram mais el evados que os da área de cerrado (Figura 1).

A forte redução no teor de carbono com o cultivo do LE1 foi acompanhada por uma diminuição da CTC medida em pH 7,0 (Quadro 1). Nas áreas cultivadas do LE 1 , a CTC na parcela-testemunha foi significativamente mais alta do que na área com calagem, apesar de as áreas Calc e Test apresentarem teores similares de carbono. 0 inesperado val or mais baixo de CTC na parcela com calagem do LE 1 pode ser explicado, em parte, pel os resultados al cançados por Silva (1997), que verificou menor presença de ácidos fúlvicos e húmicos nessa área, em relação à testemunha. Outra possível explicação para a menor CTC na área com calagem está relacionada com a maior prevalência de moléculas com baixa CTC nas camadas superficiais dos solos corrigidos, considerando a maior movimentação no perfil de solo de compostos orgâni cos com al ta densi dade de cargas (Wilczynski et al., 1993). No LE2, a redução nos teores de C com o cultivo foi também acompanhada de uma diminuição na CTC, sendo esta significativamente maior na área cultivada com a adição de fósforo.

As drásticas perdas de matéria orgânica na camada superficial $(0-10 \mathrm{~cm})$ das áreas cultivadas do LE 1 e os seus efeitos sobre a CTC revelaram a fragilidade desse solo, enfatizando a importância em se adotarem práticas de manejo que priorizem a maior permanência de restos culturais nas ár eas sob plantio, a fim de manter o nível de matéria orgânica original mente presente na floresta.

\section{Teor e distribuição de carbono, nitrogênio e enxofre nas frações granulométricas}

Os dados relativos aos teores de carbono nas unidades granulométricas do LE 1 e LE 2 são apresentados na figura 2. Os teores de carbono nas áreas cul tivadas esob vegetação natural dos sol os LE 1 e LE2 seguiram a seguinte ordem: Fr.grossa <Fr. fina <F r. intermediária, concordando com os dados apresentados por Bonde et al. (1992).

Os teores de nitrogênio nas frações granulométricas de amostras de solo do LE 1 (Figura 2) apresentaram padrões de concentração semel hantes aos de carbono. A retirada da vegetação de cerrado e o cultivo do LE 2 acarretaram diminuição nos teores de carbono e nitrogênio na fração intermediária e pequenos acréscimos nos teores desses elementos na fração fina. Diminuições acentuadas nos teores de $\mathrm{C}, \mathrm{N}$ e $\mathrm{S}$ na fração fina, intermediária e, em maior escala, na fração grossa foram os principais efeitos relacionados com o desmatamento e cultivo do solo LE 1. De acordo com Feller \& Beare (1997), em sol os argil losos, a di minuição do reservatório de carbono, com o cultivo contínuo, relaciona-se, principal mente, com a decomposição de frações orgânicas lábeis associadas à argila.

A el evação nos teores de enxofre nas áreas cultivadas do LE2 associou-se ao aumento nos teores desse elemento na fração fina e na intermediária. De modo geral, os teores de enxofre associados à fração grossa das três áreas amostradas do LE2 foram bastante reduzidos.

Com a finalidade de eliminar os efeitos de diferentes teores iniciais de carbono, nitrogênio e enxofre da área-controle, fatores de enriquecimento de $C\left(E_{C}\right), N\left(E_{N}\right)$ e $S\left(E_{S}\right)$ (Quadro 2) foram calculados para as frações (grossa, intermediária e fina), de acordo com Christensen (1992). A fração intermediária foi a mais enriquecida em carbono e 

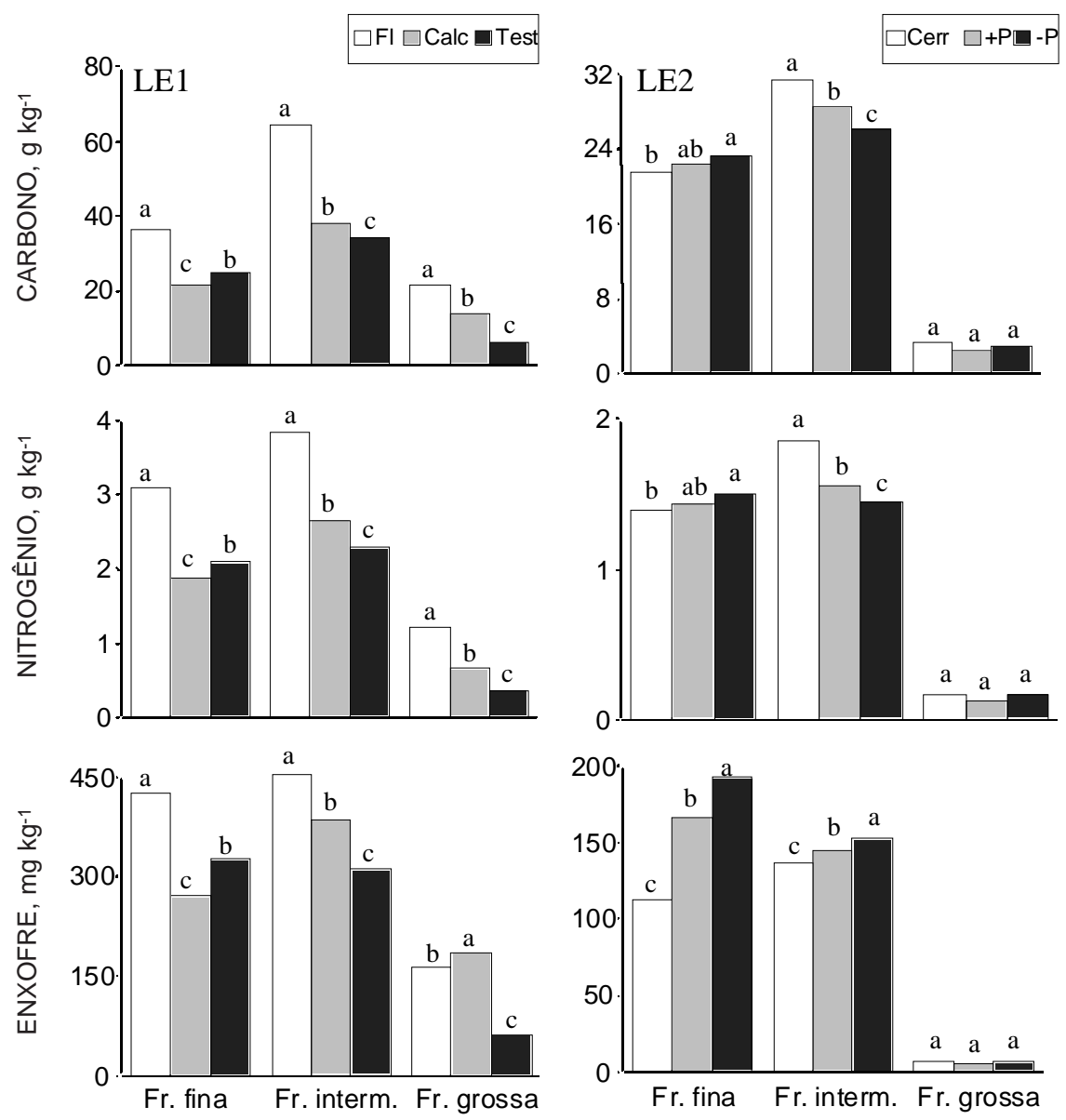

Figura 2. Concentrações de carbono, nitrogênio e enxofre nas frações granulométricas (fina, intermediária e grossa) de Latossolo Vermelho-E scuro derivado de floresta (LE 1) e de cerrado (LE 2). Médias seguidas por letras diferentes, nas colunas, para cada unidade granulométrica, diferem entre si pelo teste de Tukey a 5\%. FI =floresta; Calc =área com calagem; Test =área sem calagem; Cerr =cerrado; +P =área com fósforo; - $P$ = área sem fósforo.

Quadro 2. Fatores de enriquecimento de carbono, nitrogênio e enxofre em frações granulométricas do Latossolo Vermel ho-Escuro derivado de floresta (LE 1) e de cerrado (LE2)

\begin{tabular}{|c|c|c|c|c|c|c|c|c|c|}
\hline \multirow{2}{*}{ Solo ${ }^{(1)}$} & \multicolumn{3}{|c|}{$E_{c}{ }^{(2)}$} & \multicolumn{3}{|c|}{$E_{N}^{(2)}$} & \multicolumn{3}{|c|}{$E s^{(2)}$} \\
\hline & $0-2^{(3)}$ & $2-53$ & $53-2000$ & $0-2$ & $2-53$ & $53-2000$ & $0-2$ & $2-53$ & $53-2000$ \\
\hline \multicolumn{10}{|l|}{ LE 1} \\
\hline Floresta & 0,85 & 1,51 & 0,50 & 1,02 & 1,27 & 0,40 & 0,94 & 1,00 & 0,36 \\
\hline Com cal agem & 0,87 & 1,54 & 0,55 & 0,97 & 1,37 & 0,34 & 0,98 & 1,41 & 0,67 \\
\hline Sem cal agem & 1,11 & 1,54 & 0,28 & 1,29 & 1,41 & 0,23 & 1,07 & 1,02 & 0,20 \\
\hline \multicolumn{10}{|l|}{ LE 2} \\
\hline Cerrado & 1,05 & 1,53 & 0,16 & 1,07 & 1,43 & 0,13 & 1,20 & 1,46 & 0,06 \\
\hline$+P$ & 1,32 & 1,67 & 0,14 & 1,34 & 1,46 & 0,12 & 1,14 & 1,00 & 0,03 \\
\hline$-P$ & 1,41 & 1,58 & 0,18 & 1,46 & 1,41 & 0,16 & 1,05 & 0,84 & 0,03 \\
\hline
\end{tabular}

(1) $+\mathrm{P}$ =área com fósforo; $-\mathrm{P}$ =área sem fósforo. ${ }^{(2)} \mathrm{E}_{\mathrm{C}}$ (F ator de enriquecimento de $\mathrm{C}$ ) =(Teor de $\mathrm{C}$ na fração granulométrica analisada/ Teor de $C$ total $) ; E_{N}(F$ ator de enriquecimento de $N)=($ Teor de $N$ na fração granulométrica analisada/Teor de $N$ total $) ; E_{S}(F$ ator de enriquecimento de $\mathrm{S})=\left(\right.$ Teor de $\mathrm{S}$ na fração granulométrica analisada/Teor de S total). ${ }^{(3)}$ Faixa de diâmetro ( $\left.\mu \mathrm{m}\right)$ da unidade granulométrica. 
nitrogênio, sendo os teores de $C$ nessa fração 51 a $54 \%$ superiores, e os de $\mathrm{N}$ de 27 a $41 \%$ superiores aos teores totais de carbono e nitrogênio. Os teores de carbono na fração fina do LE 1 mostraram-se muito próximos aos teores totais desse el emento nas áreas FI, Calc e Test. No LE 2, os teores de carbono na fração fina foram de 5 a $41 \%$ mais al tos do que os teores totais desse el emento no sol o. Os val ores de $E_{C}$ obtidos para a fração fina epara a intermediária foram muito próximos aos obtidos por Bonde et al. (1992) para argila esilte, enquadrando-sena faixa devalores $(0,5$ a 11,1$)$ apresentada por Christensen (1996), em revisão avaliando diferentes classes de sol os. No caso da fração grossa, os valores do $E_{C}$ no presente estudo situaram-se um pouco acima do valor citado pelo último autor $(0,1)$, porém dentro da faixa $(0,2$ a 0,8$)$ apresentada por Guggenberger et al. (1994).

Os efeitos do cultivo de Iaranja em LE 1, pela análise dos dados de $\mathrm{E}_{C}$ e $\mathrm{E}_{N}$, restringiram-se a um empobrecimento de $\mathrm{C}$ e $\mathrm{N}$ na fração grossa e a um enriquecimento relativo desses el ementos na fração fina da área-testemunha (sem calagem). NoLE2, foi verificado um eriquecimento relativo de $\mathrm{C}$ e $\mathrm{N}$ na fração fina das áreas sob cultivo. Os dados de $E_{S}$ evidenciaram, apesar do acréscimo nos teores totais de $S$ nas áreas cultivadas do LE2, uma diminuição nas concentrações deS na fração intermediária, com concomitante enriquecimento desse elemento na fração fina. Os val ores de $E_{S}$ cal culados para a fração grossa do LE 2 foram muito baixos, evidenciando, de fato, reduzidos teores de $\mathrm{S}$ associados a essa fração granulométrica. No LE 1, os valores de $\mathrm{E}_{\mathrm{S}}$ da fração grossa e da intermediária da área com calagem aumentaram, em relação à flor esta e à testemunha, indicando maior disponibilidade deS nessas unidades granulométricas.

As diferenças entre os fatores de enriquecimento de carbono e nitrogênio das frações texturais do LE 1 são refletidas nas relações C:N obtidas (Figura 3). Independentemente da área analisada, verificou-se decréscimo das relações $C: N$ da fração grosseira para a mais fina. As relações C:N observadas para o solo mostraram-se muito próximas daquelas observadas para a fração fina, em razão da dominância dessa partícula textural no LE 1 . As menores relações C:N foram sempre observadas para a fração fina, com val ores similares àquel es normal mente encontrados nas frações orgânicas com maior grau de humificação, normal mente associadas a compostos oriundos do metabolismo de microrganismos (Baldock et al., 1992; Guggenberger et al., 1994).

Demodo geral, as relações C:N determinadas nas áreas cultivadas mostraram-se muito próximas daquelas observadas nas frações texturais da área sob floresta do LE 1, exceto na parcela com calagem, em cuja fração grossa se verificou a mais al ta relação C:N (Figura 3). É provável quea maior presença de carbono na área com calagem se deva à maior produção vegetal constatada em campo e, por $\square$ Solo (total) $\circledast$ Fr. fina $\oslash$ Fr. interm. @O Fr. grossa

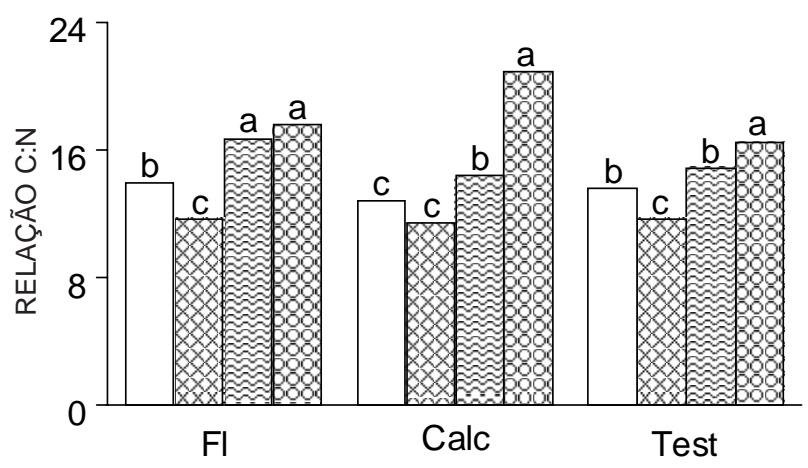

Figura 3. Relações $C$ : N em solo não fracionado e em suas frações granulométricas (fina, intermediária e grossa) de L atossolo VermelhoEscuro derivado de floresta (LE 1). Médias seguidas de letras distintas, nas colunas, para cada fração granulomética, diferem entre si pelo teste de Tukey a $5 \%$. FI = floresta; Calc = área com calagem; Test =área sem calagem.

conseguinte, à maior entrada de resíduos vegetais frescos, de relação $\mathrm{C}: \mathrm{N}$ mais alta, na área sob efeito da calagem.

Os dados de distribuição de carbono, nitrogênio e enxofre no LE1 e LE2 (Figura 4) revelaram que esses elementos encontram-se, em grande parte, associados à fração fina. Analisadas conjuntamente, a fração fina ea intermediária contribuem com mais de $90 \%$ das reservas de $\mathrm{C}, \mathrm{N}$ eS presentes nos sol os estudados. As texturas muito argilosa do LE 1 e argilosa do LE2 explicam, em parte, o fato de a maioria do carbono, nitrogênio e enxofre estar associada à fração fina nesses dois sol os, já que essa fração textural, considerando sua maior área superficial emaior densidade de cargas, exercepapel crucial na estabilização da matéria orgânica contra o ataque de microrganismos (Baldock et al., 1992; Rosell et al., 1996).

Em termos gerais, os reservatórios de carbono e nitrogênio associados à areia foram muito baixos, perfazendo menos de $10 \%$ dos estoques totais desses dois el ementos presentes nos solos estudados. Os dados de distribuição de carbono, nitrogênio e enxofrenas áreas cultivadas e sob vegetação natural do LE 1 evidenciaram, principalmente na área sem correção de acidez, maior contribuição de C e N da fração fina para os estoques totais desses nutrientes no solo, com concomitante redução de contribuição da frações grossa e intermediária. No LE 2, as perdas de carbono e nitrogênio estiveram mais associadas ao consumo desses nutrientes ligados à fração intermediária, sendo constatada nas áreas cultivadas mai or contribuição da fração fina e menor da fração intermediária, para os estoques totais 


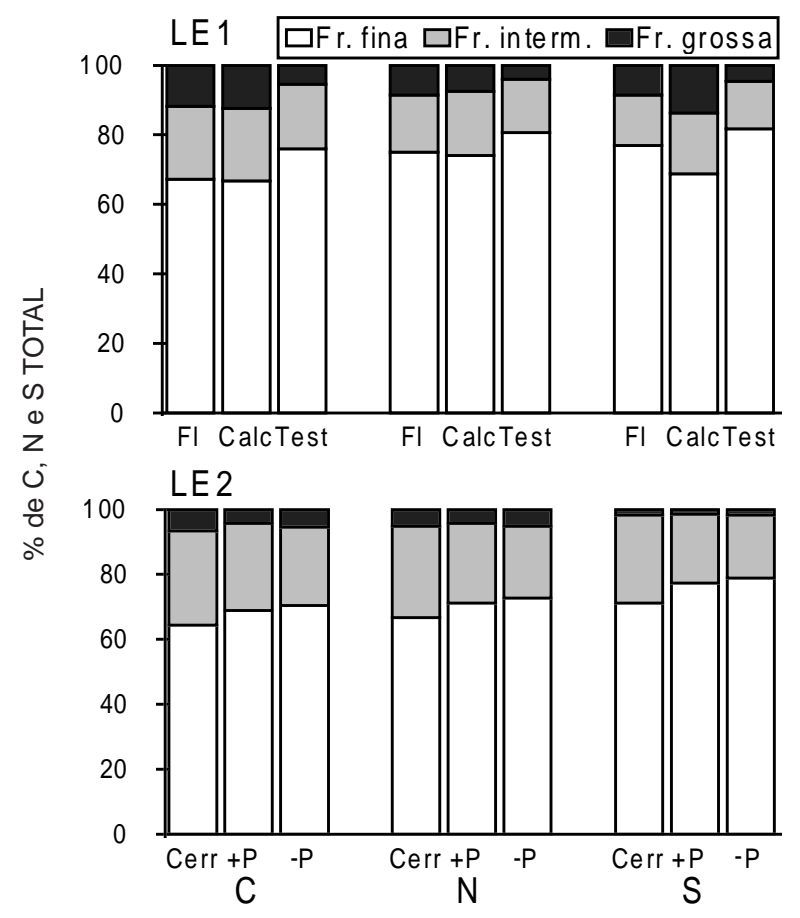

Figura 4. Distribuição relativa de carbono, nitrogênio e enxofreem frações granulométricas do solo (fina, intermediária e grossa) oriundo de áreas cultivadas e sob vegetação natural do Latossolo Vermelho-E scuro derivado de floresta (LE 1) e de cerrado (LE2). FI = floresta; Calc = área com calagem; Test $=$ área sem calagem; Cerr =cerrado; $\mathbf{+ P}=$ área com fósforo; -P = área sem fósforo.

desses nutrientes no solo. Em termos de distribuição de enxofre no LE2, o maior armazenamento desse nutriente nas áreas cultivadas esteve associado à fração fina, que teve a maior contribuição para os teores totais de enxofre nas áreas sob cerrado e cultivadas do LE 2.

Em resumo, os principais efeitos do cultivo nas áreas estudadas deveram-se à redução absol uta nos teores de carbono, nitrogênio e enxofre associados às frações (fina, intermediária e grossa) e a um enriquecimento relativo desses el ementos na fração fina, principalmente na área-testemunha do LE 1. Nesse solo, a adoção de práticas conservacionistas de manejo, com vistas em evitar perdas excessivas desolo, mostram-senecessárias, uma vez quea perda diferenciada da fração fina do solo resultaria no esgotamento das reservas de carbono, nitrogênio e enxofre, por estarem esses el ementos majoritariamente concentrados nessa fração granul ométrica. No LE2, as perdas de matéria orgânica com o cultivo foram menos drásticas. A técnica de fracionamento físico por ultra-som mostrou-se adequada para discriminar os diferentes 'pools' de matéria orgânica, permitindo mel hor visualização dos estoques de C, $\mathrm{N}$ e $\mathrm{S}$ associados às frações granulométricas dos Latossolos estudados.

\section{CONCLUSÕES}

1. Houve redução acentuada nos teores de carbono, nitrogênio, enxofre e capacidade de troca de cátions nas áreas cultivadas do solo de floresta.

2. A prática da calagem resultou em maior preservação de carbono e nitrogênio no sol o cultivado com laranja e derivado de floresta.

3. Os teores de carbono e nitrogênio foram reduzidos com o cultivo, com ou sem adição de fósforo, do solo derivado de cerrado; porém, houve maior preservação de enxofre nas áreas cultivadas, com ou sem fósforo, em relação àquela sob vegetação de cerrado nativo.

4. Os maiores reservatórios de carbono, nitrogênio e enxofre nas áreas cultivadas e sob vegetação natural dos Latossolos em estudo encontraram-se associados à fração fina $(<2 \mu \mathrm{m})$.

5. A redução nos teores de carbono, nitrogênio e enxofre nas áreas de floresta cultivadas deveu-se à decomposi ção de material orgânico associado às três frações (fina, intermediária e grossa). No solo de cerrado, as perdas de carbono e nitrogênio observadas com o cultivo estiveram associadas à decomposição de matéria orgânica ligada à fração intermediária.

\section{AGRADE CIME NTOS}

Ao Consel ho Nacional de Desenvolvimento Científico e Tecnológico (CNPq), pelos recursos cedidos ao projeto de pesquisa, e aos Pesquisadores J osé A. Quaggio e Thomas Rein, pela cessão das amostras de sol o e valiosas sugestões.

\section{LITE RATURA CITADA}

AMELUNG, W.; ZECH, W.; ZHANG, X.; FOLLETT, R.F.; TIESSEN, H.; KNOX, E. \& FLACH, K.W. Carbon, nitrogen, and sulfur pools in particle-size fractions as influenced by climate. Soil Sci. Soc. Am. J ., 62:172-181,1998.

BALDOCK, J.A.; OADES, J .M.; WATERS, A.G.; PENG, X.; VASSALLO, A.M. \& WILSON, M.A. Aspects of the chemical structure of soil organic materials as reveal ed by sol id-state 13C NMR spectroscopy. Biogeochemistry, 16:1-42, 1992.

BARDSLEY, C.E. \& LANCASTER, J .D. Determination of sulfur and soluble sulfates in soils. Soil Sci. Soc. Am. Proc., 24:265268, 1960. 
BONDE, T.A.; CHRISTENSEN, B.T. \& CERRI, C.C. Dynamics of soil organic matter as reflected by natural ${ }^{13} \mathrm{C}$ abundance in particle size fractions of forested and cultivated oxisols. Soil Biol. Biochem., 24:275-277, 1992.

BORKEN, W. \& BRUMME, R. Liming practice in temperate forest ecosystems and the effects on $\mathrm{CO}_{2}, \mathrm{~N}_{2} \mathrm{O}$ and $\mathrm{CH}_{4}$ fluxes. Soil Use Manag., 13:251-257, 1997.

CHRISTENSEN, B.T. Carbon in primary and secondary organomineral complexes. In: CARTER, M.R. \& STEWART, B.A., eds. Structure and organic matter storage in agricultural soils. Boca Raton: Lewis Publishers, 1996. p.97165.

CHRISTENSEN, B.T. Physical fractionation of soil and organic matter in primary particlesize and density separates. Adv. Soil Sci., 20:1-90, 1992.

EMPRESA BRASILEIRA DE PESQUISA AGROPECUÁRIA EMBRAPA. Serviço Nacional de Levantamento e Conservação do Solo. Manual de métodos de análise do sol o. Rio de J aneiro, 1979. 247p.

FELLER, C. \& BEARE, M.H. Physical control of soil organic matter dynamics in the tropics. Geoderma, 79:69-116, 1997.

GEE, G.W. \& BAUDER, J .W. Particle-size analysis. In: KLUTE, A., ed. Methods of soil analysis. Madison, American Society of Agronomy, 1986. p.383-411.

GUGGENBERGER, G.; CHRISTENSEN, B.T. \& ZECH, W. Landuse effects on the composition of organic matter in particlesize separates of soil: I . Lignin and carbohydratesignature. Europ. J . Soil Sci., 45:449-458, 1994.

KREUTZER, K Effects of forest liming on soil processes. Plant Soil, 168-169:447-470, 1995.

LATHWELL, D.J . \& BOULDIN, D.R. Soil organic matter and soil nitrogen behaviour in cropped soils. Trop. Agric., 58:341348, 1981.

MARSCHNER, B. \& WILCZYNSKI, A.W. The effect of liming on quantity, and chemical composition of soil organic matter in a pine forest in Berlin, Germany. Plant Soil, 137:229236, 1991.

MURATA, T.; NGUYEN, M.L. \& GOH, K.M. The effects of longterm superphosphate application on soil organic matter content and composition from an intensively managed $\mathrm{New}$ Zealand pasture. Europ. J. Soil Sci., 46:257-264, 1995.

NOBRE, C.A. \& GASH, J. Desmatamento muda clima da Amazônia. Ci. Hoje, 22:33-42, 1997.
RESCK, D.V.S.; PEREIRA, J . \& SI LVA, J .E. Dinâmica da matéria orgânica na região dos cerrados. Planaltina: EMBRAPA/ CPAC, 1991. 22p. (Documentos, 36)

ROSELL, R.A.; GALANTINI, J .A. \& IGLESIAS, J .O. Organic carbon changes in soil fractions of two texturally-different Haplustolls under cultivation. In: CLAPP, C.E.; HAYES, M.H.B.; SENESI, N. \& GRIFFITH, S.M., eds. Humic substances in soil and water environments. St. Paul, IHSS, 1996. p.161-162.

ROTH, C.H.; WILCZYNSKI, W. \& CASTRO FILHO, C. Effect of tillage and liming on organic matter composition in a Rhodic Ferralsol from southern Brazil. Z. Pflanzenerähr. Bodenkd., 155:175-179, 1992.

SHANG, C. \& TIESSEN, H. Organic matter lability in a tropical oxisol: evidence from shifting cultivation, chemical oxidation, particlesize, density, and magneticfractionations. Soil Sci., 162:795-807, 1997.

SILVA, C.A. Mineralização de nitrogênio e enxofre e caracterização de substâncias húmicas em sol os brasileiros por ${ }^{13} \mathrm{C}-\mathrm{RMN}$ e cromatografia por exclusão de tamanho. Lavras, Universidade Federal de Lavras, 1997. 82p. (Tese de Doutorado)

SILVA, J .E.; LEMAINSKI, J . \& RESCK, D.V.S. Perdas dematéria orgânica esuas relações com a capacidade de troca catiônica em sol os da região de cerrados do oeste baiano. $\mathrm{R}$. Bras. Ci. Solo, 18:541-547, 1994.

TIESSEN, H. \& STEWART, J .W.B. Partide-sizefractions and their use in studies of soil organic matter: II. Cultivation effects on organic matter composition in size fractions. Soil Sci. Soc. Am. J ., 47:509-514, 1983.

VITORELLO, V.A.; CERRI, C.C.; ANDREUX, F. \& VICTÓRIA, R.L. Organic matter and natural carbon-13 distributions in forested and cultivated oxisols. Soil Sci. Soc. Am. J ., 53:773-778, 1989.

ZONTA, E.P. \& MACHADO, A.A. SANEST - Sistema deAnálise Estatística. São Paulo, Escola Superior deAgricultura Luiz de Queiroz, 1980. (Software)

WILCZYNSKI, A.W.; RENGER, M.; J ÓZEFACIUK, G. \& HAJ NOS, M. Negative charge - $\mathrm{pH}$ dependence of organic matter of forest soil under influence of liming as determined from titration curves. Z. Pflanzenernahr. Bodenkd., 156:267271, 1993. 